Open Access

\title{
Roles of perceived fit and perceived individual learning support in students' weblogs continuance usage intention
}

Princely Ifinedo

\author{
Correspondence: \\ pifinedo@gmail.com \\ Department of Financial and \\ Information Management, Shannon \\ School of Business, Cape Breton \\ University, P. O. Box 5300, Sydney, \\ NS B1P 6L2, Canada
}

\begin{abstract}
Weblogs (or blogs) are increasingly being used in higher educational contexts. Not much is known about the factors that influence students' continued usage intention of weblogs. This study uses the expectation-confirmation model (ECM) as its background theoretical framework, and explores the roles of antecedent factors of perceived fit and perceived individual learning support in the research model. A cross-sectional survey was used to collect data from 108 undergraduate students taking a management information systems (MIS) course in a small university in Canada. Relevant hypotheses on the subject matter were formulated and tested. The partial least squares (PLS) technique was used for data analysis. The results strongly support the proposed hypotheses, indicating that perceived fit, perceived individual learning support, perceived usefulness, confirmation, and satisfaction have positive effects on students' continued usage intentions of Weblogs. The findings of this study have practical and theoretical implications, which are succinctly discussed, and suggestions for future research outlined.
\end{abstract}

Keywords: Perceived fit, Perceived individual learning support, Continuance usage intention, Weblogs, Students

\section{Introduction}

Information and communication technologies (ICT) in general, and collaborative technologies in particular, are useful resources for improving teaching and learning in the higher education sector (Ifinedo, 2007; Wagner, Hassanein, \& Head, 2008; Lai \& Chen, 2011; Bennett, Bishop, Dalgarno, Waycott, \& Kennedy, 2012; Mansouria \& Piki, 2016). Among emerging ICT used for collaborating and knowledge sharing are Web 2.0 technologies, including wikis, social networking sites, and weblogs (often shortened to "blogs") (Castaneda, Ahern, \& Díaz, 2011; Arquero \& Romero-Frías, 2013). Across the world, Web 2.0 technologies have become popular tools for the student population (Lenhart, Purcell, Smith, \& Zickuhr, 2010; Halic, Lee, Paulus, \& Spence, 2010; Bennett et al., 2012; Costa, Alvelos, \& Teixeira, 2015). A recent study reported that many students expect their instructors to use a variety of innovative ICT, including Web 2.0 tools within the learning environment (Buzzard, Crittenden, Crittenden, \& McCarty, 2011).

This study focusses attention on weblogs, which are websites that allows a user (blogger) to publish or 'post' their thoughts online or make comments on the posts of

(c) The Author(s). 2018 Open Access This article is distributed under the terms of the Creative Commons Attribution 4.0 International License (http://creativecommons.org/licenses/by/4.0/), which permits unrestricted use, distribution, and reproduction in any medium, provided you give appropriate credit to the original author(s) and the source, provide a link to the Creative Commons license, and indicate if changes were made. 
others (Hain \& Back, 2008; Cakir, 2013). Like traditional websites, weblogs have optional links to other blogs and online resources (Hain \& Back, 2008; Ifinedo \& Usoro, 2016). Unlike traditional websites, weblogs' posts appear in reverse chronological order. Additionally, weblogs have archival capabilities, i.e., new posts are created and old ones preserved (Hain \& Back, 2008; Halic et al., 2010). In order to blog, a user needs to use a blogging platform which is usually provided by a host site (e.g., Blog.com and WordPress.com).

Blogging in higher educational contexts offers several benefits. For example, studies have shown that students can improve their reflective learning and thinking through blog use (Williams \& Jacobs, 2004; Yang, 2009; Sun, 2010; Mansouria \& Piki, 2016). Robertson (2011, p. 1643) found that "the blogs enabled students to express their emotional experiences of learning and to exchange social and cognitive support with their peers." In general, students' use of blogs encourages interaction (Deng \& Yuen, 2013), collaboration (Ellison \& Wu, 2008; Shim \& Guo, 2009; Mansouria \& Piki, 2016; Zhang, Song, Shen, \& Huang, 2014) and cooperation (Zhang et al., 2014). A study showed that instructors have been able to improve learning environments by taking note of issues raised in students' blog conversations (Paulus, Payne, \& Jahns, 2009). In short, teaching effectiveness is improved by blog use (Lai \& Chen, 2011; Ifinedo \& Usoro, 2016).

In spite of the advantages of blog use in teaching and learning, there are barriers to the adoption and continued usage intention of such technologies in the higher education sector. For example, some individuals may be afraid of using new ICT for learning (Black, 2007; Luik \& Taimalu, 2016). Personal and individual characteristics have been found to be critically important in encouraging student engagement in blogging (Deng \& Yuen, 2013). Some researchers have noted that bloggers' desire to continue blogging may be short-lived. In citing Gurzick and Lutters (2006), Lu and Lee (2012, p. 1081) commented that "although many blogs survive more than one year, there are still lots of blogs discarded within a few days of being established." In higher education contexts, Luik and Taimalu (2016) noted debate among researchers as to whether blog use for learning "should be voluntary or compulsory, and whether learners are more motivated when the tasks on the blog are assessed or not." Chen, Lai, and Ho's (2015) study was designed to uncover "why some teachers have stopped using teaching blogs over time, while others continue to do so (p. 237)".

Little research has been done on students' continuance intention weblogs use for learning purposes. Studies focusing on initial adoption of such tools abound (e.g., Kaplan, Piskin, \& Bol, 2010; Deng \& Yuen, 2011; Mansouria \& Piki, 2016). It is worth stressing that initial adoption or acceptance of ICT products and the continued use of such systems are two separate issues requiring disparate attention and emphasis (Davis, 1989; Bhattacherjee, 2001). In light of the growing popularity of weblogs as supportive learning tools in higher education, it would seem pertinent to explore potential factors impacting continued usage of such technologies by students. A research effort dedicated to such an issue merits commendation.

The main purpose of this study is to investigate influences of salient factors on undergraduate students' continued intention to use weblogs for learning in a management information systems (MIS) course. Although research has examined students' adoption of weblogs in a variety of undergraduate level courses, including chemistry (Benedict \& Pence, 2012), education (Coutinho, 2007; Mansouria \& Piki, 2016), 
marketing (Kaplan et al., 2010), foreign languages (Castaneda et al., 2011; Al Waely \& Aburezeq, 2013; Zhang et al., 2014), and so forth (Deng \& Yuen, 2011), not much is known about the undergraduate students' adoption and continued intention to use blogs in MIS classes. MIS was chosen for this study mainly for illustrative purposes and to complement and diversify insights on students' use of weblogs at the undergraduate level.

Empirical findings from this study will contribute to the growing body of knowledge on students' continued reuse of technologies in higher learning environments. To guide this research effort, this study will draw from Bhattacherjee's (2001) expectation-confirmation model (ECM), which is augmented with two intrinsic motivational antecedents: perceived fit and perceived individual learning support. Intrinsic motivation refers to motivation that comes from inside an individual rather than from external or outside factors (Brown, 2007). Previous studies showed that ECM and the two intrinsic factors are relevant in explaining students' acceptance of ICT-supported learning environments, including where weblogs are in use (Cho, Cheng, \& Lai, 2009; Cheng, Wang, Yang, Kinshuk, \& Peng, 2011; Lin, 2012; Chen et al., 2015).

\section{Background information and theoretical foundations Weblogs use in higher educational settings}

The literature (e.g., Coutinho, 2007) indicates that blog use in learning spaces was inspired by Vygotsky's (1978) social constructivist learning theory. Social constructivism emphasizes a balance between a learner's autonomy and learning in a social context, community or space. Notably, an individual learning in such an environment has the opportunity to discuss their thoughts, ideas, and opinions, and at the same time, acquire and accumulate knowledge through self-reflection and interaction, collaboration, and cooperation with others (Castaneda et al., 2011; Arquero \& Romero-Frías, 2013; Mansouria \& Piki, 2016). Suffice it to say that active learning ensues where such ideals are enabled.

In citing Chickering and Gamson (1987), Cakir (2013) contended that active learning, interaction, collaboration between students, and feedback are among the key principles used to engage students in higher education. Cakir commented that implementing these ideals in educational learning environments without proper tools to support faculty and learners is a major challenge. He argued that weblogs are tools to mitigate such a challenge. Weblogs are open systems that use simple user interfaces which include a variety of features (e.g., text, graphics, audio, and video clips) (Lai \& Chen, 2011). Perhaps due to their simplicity, students and instructors have come to accept weblogs as essential and innovative tool in the learning environment (Ellison \& Wu, 2008; Paulus et al., 2009; Lai \& Chen, 2011; Zhang et al., 2014; Mansouria \& Piki, 2016).

In the context of higher education, Herrington and Oliver (2000) asserted that weblogs can improve and support highly effective types of learner-to-learner interactions. Likewise, weblogs have been used to enhance communication between students and instructors (Kim, 2008). This researcher noted that weblogs are often employed by educators to overcome the inadequacies (e.g., lack of sense of ownership and archival capabilities) that exist in other ICT, such as computer-mediated communication applications used in learning spaces. It is worth noting that weblogs facilitate student learning by enhancing a space "where a greater understanding of student meaning making can be gained" (Paulus et al., 2009, p. 13). 
The student learning experience and the ability they have to communicate and express thoughts with instructors and peers are enhanced by course blogs (Halic et al., 2010). Mansouria and Piki (2016) noted that university students who use weblogs "have the autonomy to create and express themselves (online) and share their views with their peers and lecturers in efficient and meaningful ways" (p. 262). Chen et al. (2015, p. 237) provided evidence indicating that weblogs in education have been used "to explain a concept more clearly with a combination of words and pictures or videos", broadcast and manage class activities, and communicate and interact effectively with students. In sum, there is growing literature discussing self-reflection, interaction, collaboration, and cooperation as main benefits derived from weblog usage in higher educational settings; some examples were mentioned earlier.

\section{The expectation-confirmation model (ECM)}

Oliver (1980) proposed the expectation-confirmation theory (ECT) in marketing literature to study consumer satisfaction and repurchase intention behaviors. ECT assumes that satisfaction has a central role in explaining repurchasing behavior. In adapting ECT, Bhattacherjee (2001) proposed the expectation-confirmation model (ECM) of information systems (IS) continuance to explain users' intention to reuse an IS. He incorporated the construct of perceived usefulness of IS from the technology acceptance model (Davis, 1989). His model posits that user satisfaction with IS is positively influenced by confirmation of expectations, which impacts perceived usefulness of IS. Perceived usefulness is an antecedent of both satisfaction and IS continuance intention, and user satisfaction has a positive effect on IS continuance intention.

In this study, user satisfaction refers to the extent to which a student learning MIS is pleased with the use of weblogs in the course (Liao, Huang, \& Wang, 2015). Perceived usefulness refers to extent to which a student learning MIS believes that using weblogs would enhance his or her learning performance in the course (Davis, 1989; Lin, 2012). Confirmation refers to the extent to which a student's initial expectations about the performance of using weblogs to learn MIS is being confirmed after having an experience with such tools (Bhattacherjee, 2001; Lee, 2010). Continuance usage intention refers to a student's subjective likelihood of continuing to use weblogs to learn MIS (Bhattacherjee, 2001).

Fundamentally, ECM is based on extrinsic motivations (e.g., perceived usefulness and user satisfaction). The roles of intrinsic motivation and person-technology fit are ignored in ECM (Hung, Chang, \& Hwang, 2011). This shortcoming explains why researchers who used ECM to study the continued usage intention of IS, ICT-enabled learning technologies, and weblogs often augment the model with relevant motivational variables, including perceived self-efficacy, habit, perceived performance, perceived fit, and so forth (Wu, Tsai, Chen, \& Wu, 2006; Limayem \& Cheung, 2008; Sørebø, Halvari, Gulli, \& Kristiansen, 2009; Lee, 2010; Lin, 2012; Lin, \& Wang, CH., 2012; Tang, Tang, \& Chiang, 2014; Chen et al., 2015; Liao et al., 2015).

\section{Perceived fit}

In organizational literature, person-environment (P-E) fit is used to describe the extent to which individual and environmental characteristics match (Kristof-Brown, 
Zimmerman, \& Johnson, 2005). In organizational studies, an individual's perception of P-E fit has been found to be related to job commitment and satisfaction (Edwards, 2008). In the IS domain, Goodhue and Thompson (1995) proposed the task-technology fit (TTF) theory, which suggests that IS is more likely to have a positive impact on individual performance and the use of IS if the capabilities of the IS match the tasks that the user must perform with the IS. TTF has been shown to be relevant to e-learning environments (Akkoyunlu \& Soylu, 2008; Lai, Wang, \& Lei, 2012). Some researchers (e.g., Lin, 2012; Lin, \& Wang, CH., 2012) who drew from TTF used "perceived fit" to denote person-technology fit. These researchers found that perceived fit motivates learners to continue utilizing e-learning systems. In this study, perceived fit refers to the extent to which a student learning MIS believes that weblog use matches his or her learning characteristics and requirements.

\section{Perceived individual learning support}

Competency-based learning (or competency-based education and training) is an approach to teaching and learning that is used in many fields and learning environments (Draganidis \& Mentzas, 2006; Cheng et al., 2011). The CBL approach focuses on the development of specific competencies for the learner (Horton, 2000). It allows individuals working at their own pace to learn skills they consider challenging (Draganidis \& Mentzas, 2006). Related to CBL is learner control (LC), which emphasizes the individualization of instruction and facilitates active learning (Merrill, 1975).

According to Cheng et al. (2011, p. 1318), e-learning design literature "suggests that learner control of learning and customization of learning experiences will meet learners' needs and preferences and improve learners' satisfaction and motivation [to continuing using such platforms]." Thus, using both approaches, a learner can construct or build new knowledge and identify learning needs deserving of attention. Cheng et al. (2011) asserted that lack of consideration for learners' perceptions and attitudes toward e-learning systems have led to unsuccessful design and implementation of such initiatives. These researchers based their research study on CBL and LC and used the term "perceived individual learning support", which they showed had a significant effect on intention to use e-learning applications. Accordingly, perceived individual learning support is considered pertinent to this study; it refers to the extent to which a student learning MIS believes weblogs would improve his or her learning performance and outcome.

\section{Research model and hypotheses}

Based on the foregoing discussion, the study's research conceptualization or model, which fuses perceived fit and perceived individual learning support with ECM, is proposed (Figure 1). The proposed research model is in accordance with past efforts that integrated TTF, ECM, and individual learning support (e.g., McGill \& Hobbs, 2008; Lin, \& Wang, CH., 2012; Cheng, 2014). The study's hypotheses are highlighted in the research model.

Students may not accept a newly introduced technology in their learning environment if they perceived the tool to be inconsistent with the way they learn (McGill \& Hobbs, 2008; Lai et al., 2012). The existence of a positive relationship between learning 


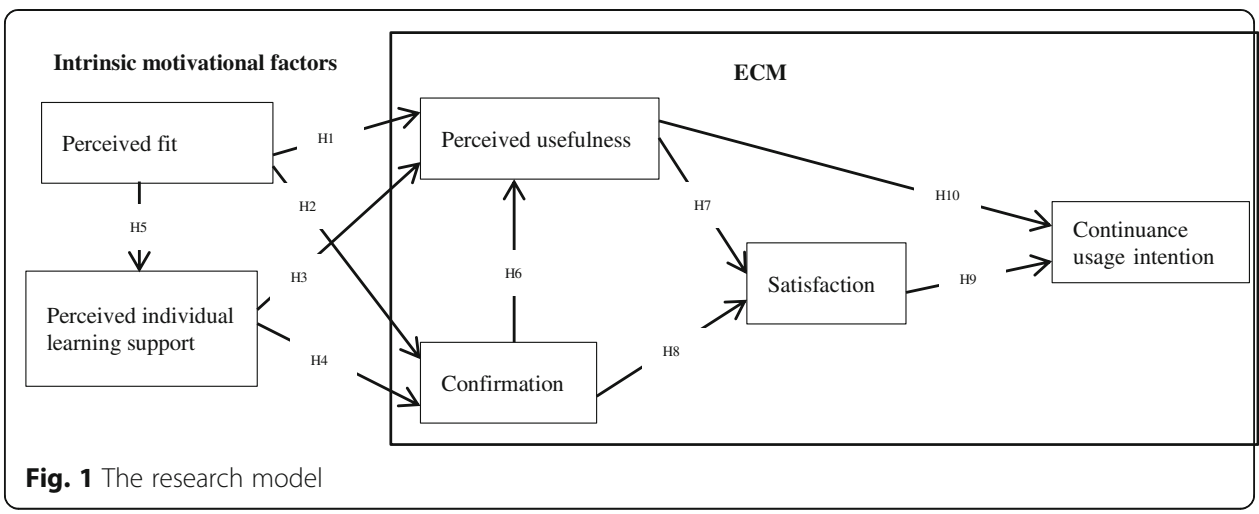

styles and students' preference for and confidence in technology use has been demonstrated (Ames, 2003; Akkoyunlu \& Soylu, 2008). It is expected that students will appreciate the usefulness of weblogs for learning MIS, if they believe the technology fits with the way they learn the subject. A number of previous studies have shown that perceived fit (sometimes represented as perceived compatibility or educational compatibility) positively impacts perceived usefulness of learning applications (Chen, 2011; Lai \& Chen, 2011; Lin, \& Wang, CH., 2012). Therefore, for students using weblogs to learn in an MIS course, the following hypothesis is proposed:

H1: Perceived fit has a positive effect on perceived usefulness of weblogs.

With regard to learning goals and outcomes, perceived fit between technology and tasks carried out by students and instructors in learning environments has been shown to be positively related (McGill \& Hobbs, 2008; Terzis, Moridis, \& Economides, 2013). User compatibility with learning systems and confirmed expectations of such tools has been shown to be positively associated (McGill \& Klobas, 2009; Lin, \& Wang, CH., 2012). Past studies revealed the existence of a positive relationship between perceived fit and confirmation of the expected consequences of technology use in learning environments (e.g., McGill \& Hobbs, 2008; McGill \& Klobas, 2009; Lin, \& Wang, CH., 2012; Terzis et al., 2013) Therefore, for students using weblogs to learn in a MIS course, the following hypothesis is proposed:

H2: Perceived fit has a positive effect on confirmation of expectations of using weblogs.

Individuals accept new technologies if the relative advantages of such are known or appreciated (Davis, 1989). It is expected that students' willingness to use weblogs in learning environments will increase if the usefulness of such tools in enhancing learning performance and effectiveness is tangible. Evidence exists to support the view indicating that perceived usefulness of learning systems is high where perceived individual support systems are available (Cheng et al., 2011). Support systems in learning environments manifest in various forms, including perceived competence with technologies, quality user-interface design features, and affinity with computing devices (Sørebø et al., 2009; Cho et al., 2009; Liu, Chen, Sun, Wible, \& Kuo, 2010; Cheng et al., 2011). Recently, Lowe, D'alessandro, Winzar, Laffey, and Collier (2013) provided evidence to 
show that affinity with computing devices positively impacted students' perceived usefulness of using Web 2.0 technologies to learn in marketing classes. Therefore, for students using weblogs to learn in a MIS course, the following hypothesis is proposed:

H3: Perceived individual learning support has a positive effect on perceived usefulness of weblogs.

ICT, with capabilities to leverage tenets of LC and CBL (e.g., the creation of new insights and identification of learning needs for a learner) either through self-reflection or collaboration, can increase learners' motivation to use such technologies (Cheng et al., 2011). Perceived individual learning support encompasses user-interface design, systems support, and functionality (Cho et al., 2009; Liu et al., 2010; Cheng et al., 2011). In general, easy to use technologies with quality supportive design features (like the ones available in blogging tools) enhance interaction between users and such systems (Halic et al., 2010; Liu et al., 2010; Cheng et al., 2011). Perceptions of value, quality, functionality, and usability of e-learning technologies were found to have positive effect on students' confirmation of the benefits of such tools (Chiu, Hsu, Sun, Lin, \& Sun, 2005; Tao, Cheng, \& Sun, 2009; Ifinedo, 2016). Therefore, for students using weblogs to learn in a MIS course, the following hypothesis is proposed:

H4: Perceived individual learning support has a positive effect on confirmation of expectations of using weblogs.

As noted, students' perceived fit with technology and tasks carried out on such systems are positively related (McGill \& Hobbs, 2008; Lin, \& Wang, CH., 2012; Terzis et al., 2013). Likewise, students' attitudes toward the use of technology impact their usage behaviors of such tools in learning environments (Au \& Enderwick, 2000). Previous research has indicated that students' learning styles and confidence in using technologies as well as their perceptions of value, quality, and usability of e-learning technologies are positively linked (Ames, 2003; Chiu et al., 2005; Ifinedo, 2016; Akkoyunlu \& Soylu, 2008; McGill \& Hobbs, 2008; Terzis et al., 2013; Cheng et al., 2011). Thus, it is expected that there will be a positive relationship between a good person-technology fit and favourability with perceptions of the value, quality, functionality, and usability of technologies. Therefore, for students using weblogs to learn in a MIS course, the following hypothesis is proposed:

H5: Perceived fit has a positive effect on perceived individual learning support in the context of weblog usage.

After interacting with a technology, an individual is better placed to determine if the tool has met their initial expectations (Bhattacherjee, 2001). ECM posits that perceived usefulness of IS increases with confirmation of the existence of the expected benefits of using such systems. Previously, several researchers have affirmed that confirmation has a positive effect on the perceived usefulness of a wide range of ICT, including those used in learning contexts (e.g., Chiu et al., 2005; Limayem \& Cheung, 2008; Sørebø et al., 2009; Lee, 2010; Terzis et al., 2013). With respect to weblogs, Tang et al. (2014) found that confirmation has a strong influence on the perceived usefulness of blog use for learning. Chen et al. (2015) also revealed that perceived usefulness of teaching blogs 
was positively impacted by confirmation of the expected benefits derived from using such tools. Therefore, for students using weblogs to learn in a MIS course, the following hypothesis is proposed:

H6: Confirmation has a positive effect on perceived usefulness of weblogs.

Consistent with the postulates of ECM, students' satisfaction with IS use is high if they appreciate the perceived advantages of such tools. By the same token, satisfaction with a technology is high if students are able to confirm their initial expectations of the benefits of using the technology. Prior studies of ICT-enabled learning environments provided strong support of importance of perceived usefulness of ICT and users' satisfaction with such technologies (e.g., Limayem \& Cheung, 2008; Sørebø et al., 2009; Lee, 2010; Stone \& Baker-Eveleth, 2013). In fact, confirmation was reported to be a key determinant of students' satisfaction with ICT-enabled learning systems (e.g., Limayem \& Cheung, 2008; Sørebø et al., 2009; Lee, 2010; Stone \& Baker-Eveleth, 2013; Cheng, 2014; Liao et al., 2015). Previous studies of blog learning and teaching also showed that perceived usefulness and confirmation are important predictors of satisfaction with weblog use (e.g., Tang et al., 2014; Chen et al., 2015). Therefore, for students using weblogs to learn in a MIS course, the following hypotheses are proposed:

H7: Perceived usefulness has a positive effect on satisfaction with weblogs.

H8: Confirmation has a positive effect on satisfaction with weblogs.

ECM research showed that continuance usage intention of IS was determined primarily by satisfaction with previous experience with IS and secondarily by perceived usefulness of IS (Bhattacherjee, 2001; Sørebø et al., 2009; Cheng, 2014; Chen et al., 2015). Broadly, satisfaction with IS influences users' attitudes and intentions to reuse a technology (Bhattacherjee, 2001). Likewise, perceived usefulness of IS leads to initial acceptance and continued usage behaviors (Davis, 1989; Bhattacherjee, 2001). Prior studies have found that both satisfaction with, and perceived usefulness of IS, strongly influence on students' continued intention to use learning technologies in higher educational contexts (e.g., Ifinedo, 2007; Limayem \& Cheung, 2008; Stone \& Baker-Eveleth, 2013; Cheng, 2014; Liao et al., 2015). Similar results were reported for weblog use for teaching and learning purposes (e.g., Tang et al., 2014; Chen et al., 2015; Ifinedo, 2016). Therefore, for students using weblogs to learn in a MIS course, the following hypotheses are proposed:

H9: Satisfaction has a positive effect on weblogs' continuance usage intention.

H10: Perceived usefulness has a positive effect on weblogs' continuance usage intention.

\section{Research method}

\section{Procedure and participants}

A survey research design was used to investigate students' perceptions of and experiences with weblog use in a MIS course at a small university (i.e., with an average class 
size of 25) in the Canadian province of Nova Scotia. Each student in the course was asked to create a blog on any concept taken from the course textbook. Uniqueness in blog content was emphasized. Students were instructed to review the blogs of peers and provide appropriate feedback or comments. The instructor read all blog posts and provided feedback as well. To motivate students, the instructor informed them that the multiple-choice section of the class tests will include items taken from student blogs. Marks were also awarded for the following: (a) quality of created blogs and (b) quality of comments and feedback provided to peers.

At the end of the course, the instructor applied for and received research ethics board approval from their university to survey students' perceptions on the issue. The questionnaire was self-administered and participation was voluntary. Students were instructed to provide candid opinions on the issues covered in the questionnaires. The average response rate for the MIS classes used for the study is $94 \%$. Data was collected from four classes taught by the researcher (instructor). The results of a Chi square test (significant at $p<0.5$ ) did not indicate differences in students' opinions on the issues under investigation across the four classes.

The study's participants were all undergraduate students $(n=108)$. They were mainly third and fourth year students. The participants were all Bachelor of Business Administration (BBA) students. $81.5 \%$ of participants (88) have 8 or more years' experience using the Internet. $32.4 \%, 59.3 \%$, and $8.3 \%$ of the students used Blog.com, WordPress.com and other blogging sites, respectively for the assignment. The rest of participants' demographic profile is shown in Table 1.

\section{Instrument development}

To ensure content validity, items previously validated in the literature were used to operationalize the study's constructs. Items used to represent perceived fit were adapted from McGill and Hobbs (2008) and Lin (2012). Perceived individual learning support was represented by items obtained from Cheng et al. (2011). Measures were taken from

Table 1 The participant's demographic profile

\begin{tabular}{llll}
\hline Measure & Category & Number & Percent \\
\hline Gender & Male & 51 & 47.2 \\
Age & Female & 57 & 52.8 \\
& Less than 18 years & 0 & 0 \\
& $19-21$ years & 55 & 50.9 \\
& $22-24$ years & 36 & 33.3 \\
& 25-27 years & 5 & 4.6 \\
Year of study & Above 27 years & 12 & 11.1 \\
& Year 1 & 2 & 1.9 \\
& Year 2 & 13 & 12.0 \\
Familiar with blog use in learning before taking the course & Year 3 & 53 & 49.1 \\
& Year4 & 39 & 36.1 \\
& Missing & 1 & 0.9 \\
\hline
\end{tabular}


Davis (1989), Lee (2010), and Bhattacherjee (2001) for the items used to operationalize the constructs of perceived usefulness, satisfaction, and confirmation. To measure continuance usage intention, measuring items adapted from Cheng et al. (2011) and Tang et al. (2014) were used. All the questionnaire items used a seven-point Likert-type scale ranging from strongly disagree (1) to strongly agree (7). Table 2 shows the items used in the questionnaire and their descriptive statistics.

Table 2 The questionnaire's items, their descriptive statistics and item loadings

\begin{tabular}{|c|c|c|c|c|c|}
\hline Construct & $\begin{array}{l}\text { Item } \\
\text { no. }\end{array}$ & Item description & Mean & $\begin{array}{l}\text { Standard } \\
\text { deviation }\end{array}$ & $\begin{array}{l}\text { Item } \\
\text { loading }\end{array}$ \\
\hline \multirow[t]{4}{*}{ Perceived fit } & PIF_1 & Using blogs fit well with learning MIS. & 5.370 & 1.181 & 0.929 \\
\hline & PIF_2 & $\begin{array}{l}\text { Using blogs fit well with helping me to be } \\
\text { efficient in learning MIS. }\end{array}$ & 5.028 & 1.443 & 0.879 \\
\hline & PIF_3 & Using blogs is compatible with my learning MIS. & 5.130 & 1.305 & 0.967 \\
\hline & PIF_4 & $\begin{array}{l}\text { Using blogs has provided me with a good } \\
\text { opportunity to learn MIS well. }\end{array}$ & 4.972 & 1.424 & 0.889 \\
\hline \multirow[t]{3}{*}{$\begin{array}{l}\text { Perceived individual } \\
\text { learning support }\end{array}$} & PID_1 & $\begin{array}{l}\text { Blogging would help me construct or build } \\
\text { knowledge needed for my MIS course. }\end{array}$ & 5.046 & 1.423 & 0.992 \\
\hline & PID_2 & $\begin{array}{l}\text { Using blogging would enhance my effectiveness } \\
\text { in learning MIS. }\end{array}$ & 5.102 & 1.387 & 0.986 \\
\hline & PID_3 & $\begin{array}{l}\text { Blogging would help me identify knowledge } \\
\text { gaps or learning needs in my MIS course. }\end{array}$ & 4.991 & 1.411 & 0.982 \\
\hline \multirow[t]{4}{*}{$\begin{array}{l}\text { Perceived } \\
\text { usefulness }\end{array}$} & PUS_1 & $\begin{array}{l}\text { Using blogs for my MIS course improved my } \\
\text { learning performance in that subject. }\end{array}$ & 5.139 & 1.363 & 0.951 \\
\hline & PUS_2 & $\begin{array}{l}\text { Using blogs for my MIS course increased my } \\
\text { learning effectiveness in that subject. }\end{array}$ & 5.148 & 1.338 & 0.956 \\
\hline & PUS_3 & Using blogs helped me learn MIS better. & 5.009 & 1.469 & 0.932 \\
\hline & PUS_4 & $\begin{array}{l}\text { Using blogs in my MIS course are helpful in } \\
\text { preparing for quizzes/tests. }\end{array}$ & 5.084 & 1.591 & 0.92 \\
\hline \multirow[t]{4}{*}{ Confirmation } & $\mathrm{COF}_{-} 1$ & $\begin{array}{l}\text { My experience with using blogs was better } \\
\text { than what I expected. }\end{array}$ & 5.028 & 1.463 & 0.911 \\
\hline & COF_2 & $\begin{array}{l}\text { Using blogs for learning in my MIS class was } \\
\text { better than I expected. }\end{array}$ & 5.111 & 1.543 & 0.899 \\
\hline & COF_3 & $\begin{array}{l}\text { The service provided by blog sites was better } \\
\text { than what I expected. }\end{array}$ & 4.718 & 1.599 & 0.82 \\
\hline & $\mathrm{COF}_{-} 4$ & $\begin{array}{l}\text { Overall, most of my expectations regarding } \\
\text { using blogs in my MIS course were confirmed. }\end{array}$ & 5.140 & 1.232 & 0.789 \\
\hline \multirow[t]{5}{*}{ Satisfaction } & SAT_1 & I am satisfied with blogs as learning tools. & 5.176 & 1.359 & 0.981 \\
\hline & SAT_2 & $\begin{array}{l}\text { I am satisfied with blogs as tools for creating } \\
\text { and sharing knowledge. }\end{array}$ & 5.449 & 1.305 & 0.995 \\
\hline & SAT_3 & I feel satisfied using blogs for my MIS course. & 5.352 & 1.396 & 0.992 \\
\hline & SAT_4 & $\begin{array}{l}\text { I am happy I used blogs for learning in my } \\
\text { MIS class. }\end{array}$ & 5.352 & 1.356 & 0.887 \\
\hline & SAT_5 & $\begin{array}{l}\text { I am pleased with the experience of using blogs } \\
\text { for my MIS course. }\end{array}$ & 5.528 & 1.322 & 0.957 \\
\hline \multirow[t]{4}{*}{$\begin{array}{l}\text { Continuance usage } \\
\text { intention }\end{array}$} & CUI_1 & $\begin{array}{l}\text { If I could, I would like to continue using blogs } \\
\text { in my learning activities in the future. }\end{array}$ & 4.639 & 1.579 & 0.995 \\
\hline & CUI_2 & $\begin{array}{l}\text { If possible, I would prefer to continue using blogs } \\
\text { in my courses in the future }\end{array}$ & 4.556 & 1.596 & 0.981 \\
\hline & CUI_3 & $\begin{array}{l}\text { I will strongly recommend that others use blogs } \\
\text { for learning. }\end{array}$ & 4.648 & 1.614 & 0.972 \\
\hline & CUI_4 & $\begin{array}{l}\text { Given that I have access to blogs in my courses, I } \\
\text { intend to use them. }\end{array}$ & 4.519 & 1.597 & 0.959 \\
\hline
\end{tabular}

The item loadings in bold font indicate entries with significant results for that specific factor or construct 


\section{Data analysis}

The partial least squares (PLS) technique of structural equation model (SEM) (Hair, Ringle, \& Sarstedt, 2011) was used to test the study's hypotheses. PLS is used because it does not require a large sample size and is more suitable for hypothesis testing than other SEM techniques (Hair, Black, Babin, \& Anderson, 2010; Hair et al., 2011). PLS provides information on the measurement and structural models.

In the measurement model, information about the reliability and validity of the constructs and their measures, are provided. WarpPLS 5.0 software (Kock, 2015) was used to conduct PLS analysis. The reliability of measures was evaluated with Cronbach's Alpha $(\alpha)$ and composite reliability values. Values of 0.7 or greater indicate a good reliability of measures (Hair et al., 2011). Convergent validity and discriminant validity, which show distinct nature of the models' constructs was assessed. In assessing the validity of the constructs, it is recommended that a construct's Average Variance Extracted (AVE) be higher than 0.5, and the AVE's squared root of each construct exceed its correlation coefficient with the other constructs in the model (Fornell \& Larcker, 1981). Standardized item loadings exceeding 0.707 strengthen the validity of constructs (Hair et al., 2011). Notably, measurement items should load highly $(>0.70)$ on their theoretically assigned construct and lowly ( $\leq 0.30)$ on other constructs (cross loadings) (Gefen \& Straub, 2005; Hair et al., 2010). Tables 2, 3, and 4 indicate that the results obtained for the measurement model have sufficient psychometric properties and meet required standards.

Information provided in structural models includes the regression coefficient, i.e., beta $(\beta)$, path significance, and the squared-R $\left(R^{2}\right)$ values, which shows the model's ability in explaining the variation in the dependent variable. $R^{2}$ values of 0.20 and higher indicate substantive influence. The WarpPLS 5.0 results for the model are shown in Fig. 2. All the ten (10) formulated hypotheses were significantly supported. The results show that the amount of variance explained by the interaction of the independent constructs in the model ranged from $52 \%$ to $76 \%$. The main information indicates that the amount of variance in the study's dependent variable (i.e., continuance usage intention) explained by perceived usefulness and satisfaction is $57 \%$.

Discussion The goal of this study was to examine factors impacting undergraduate students' continuance intention to use weblogs for learning in a MIS course. The result

Table 3 Composite Reliability, Cronbach Alphas, AVEs, and inter-construct correlations

\begin{tabular}{llllllllll}
\hline & COM & CRA & AVE & PFI & PID & PUS & COF & SAT & CUI \\
\hline PFI & 0.949 & 0.928 & 0.823 & $\mathbf{0 . 9 0 7}$ & 0.764 & 0.838 & 0.674 & 0.797 & 0.588 \\
PID & 0.972 & 0.956 & 0.919 & 0.764 & $\mathbf{0 . 9 5 9}$ & 0.744 & 0.633 & 0.708 & 0.64 \\
PUS & 0.964 & 0.950 & 0.870 & 0.838 & 0.744 & $\mathbf{0 . 9 3 3}$ & 0.705 & 0.784 & 0.601 \\
COF & 0.869 & 0.794 & 0.628 & 0.674 & 0.633 & 0.705 & $\mathbf{0 . 7 9 3}$ & 0.751 & 0.687 \\
SAT & 0.969 & 0.959 & 0.860 & 0.797 & 0.708 & 0.784 & 0.751 & $\mathbf{0 . 9 2 7}$ & 0.722 \\
CUI & 0.965 & 0.952 & 0.873 & 0.588 & 0.64 & 0.601 & 0.687 & 0.722 & $\mathbf{0 . 9 3 4}$ \\
\hline
\end{tabular}

Note:

a) $\mathrm{COM}=$ composite reliability; $\mathrm{CRA}=$ Cronbach's alpha; $\mathrm{AVE}=$ average variance extracted; $\mathrm{PFI}=$ perceived fit; $\mathrm{PID}=$

Perceived individual learning support; PUS = perceived usefulness; COF = confirmation; $\mathrm{SAT}=$ satisfaction; $\mathrm{CUI}=$

continuance usage intention;

b) Off-diagonal elements are correlations among constructs;

c) The bold fonts in the leading diagonals are the square root of AVEs 
Table 4 Item loadings and cross-loadings

\begin{tabular}{lllllll}
\hline & PIF & PID & PUS & COF & SAT & CUI \\
\hline PIF_1 & $\mathbf{0 . 9 2 9}$ & 0.112 & -0.288 & -0.12 & 0.13 & -0.101 \\
PIF_2 & $\mathbf{0 . 8 7 9}$ & -0.062 & 0.402 & 0.203 & -0.144 & 0.011 \\
PIF_3 & $\mathbf{0 . 9 6 7}$ & -0.001 & -0.236 & 0.008 & -0.086 & 0.049 \\
PIF_4 & $\mathbf{0 . 8 8 9}$ & -0.095 & 0.423 & -0.063 & 0.129 & 0.045 \\
PID_1 & -0.021 & $\mathbf{0 . 9 9 2}$ & 0.089 & -0.047 & 0.068 & -0.021 \\
PID_2 & -0.049 & $\mathbf{0 . 9 8 6}$ & -0.018 & 0.129 & 0.047 & -0.073 \\
PID_3 & 0.067 & $\mathbf{0 . 9 8 2}$ & -0.065 & -0.08 & -0.109 & 0.089 \\
PUS_1 & -0.148 & -0.033 & $\mathbf{0 . 9 5 1}$ & -0.097 & 0.245 & -0.048 \\
PUS_2 & -0.141 & -0.029 & $\mathbf{0 . 9 5 6}$ & -0.186 & 0.167 & 0.049 \\
PUS_3 & 0.218 & 0.079 & $\mathbf{0 . 9 3 2}$ & 0.249 & -0.123 & 0.017 \\
PUS_4 & 0.148 & 0.009 & $\mathbf{0 . 9 2}$ & 0.122 & -0.342 & -0.016 \\
COF_1 & 0.052 & -0.217 & 0.201 & $\mathbf{0 . 9 1 1}$ & 0.207 & -0.19 \\
COF_2 & 0.131 & -0.009 & -0.153 & $\mathbf{0 . 8 9 9}$ & 0.375 & -0.1 \\
COF_3 & -0.231 & -0.163 & -0.013 & $\mathbf{0 . 8 2}$ & -0.227 & 0.442 \\
COF_4 & 0.036 & 0.431 & -0.055 & $\mathbf{0 . 7 8 9}$ & -0.413 & -0.128 \\
SAT_1 & -0.142 & -0.005 & 0.09 & 0.095 & $\mathbf{0 . 9 8 1}$ & 0.031 \\
SAT_2 & -0.053 & 0.023 & 0.047 & -0.058 & $\mathbf{0 . 9 9 5}$ & 0.034 \\
SAT_3 & 0.006 & 0.032 & -0.095 & 0.056 & $\mathbf{0 . 9 9 2}$ & -0.059 \\
SAT_4 & 0.319 & 0.029 & -0.138 & 0.285 & $\mathbf{0 . 8 8 7}$ & -0.101 \\
SAT_5 & -0.059 & -0.06 & 0.067 & -0.26 & $\mathbf{0 . 9 5 7}$ & 0.068 \\
CUI_1 & 0.005 & -0.066 & -0.015 & -0.074 & 0.009 & $\mathbf{0 . 9 9 5}$ \\
CUI_2 & -0.094 & -0.031 & -0.038 & -0.063 & 0.151 & $\mathbf{0 . 9 8 1}$ \\
CUI_3 & -0.116 & 0.149 & 0.12 & 0.067 & -0.04 & $\mathbf{0 . 9 7 2}$ \\
CUI_4 & 0.215 & -0.03 & -0.054 & 0.096 & -0.147 & $\mathbf{0 . 9 5 9}$ \\
\hline & & & & & \\
\hline
\end{tabular}

shows that a student's perceived fit with weblogs has a positive effect on his or her perception of the usefulness of such tools in learning MIS; Thus H1 is supported. This finding is in line with observations in the extant literature indicating that learners' compatibility, styles, and fit are positively linked to their perceived usefulness of learning technologies (Akkoyunlu \& Soylu, 2008; Lai \& Chen, 2011; Lin, \& Wang, CH., 2012).

As predicted for $\mathrm{H} 2$, perceived fit was shown to have a significant effect on confirmation. That is, students learning MIS with weblogs are able to confirm the benefits of

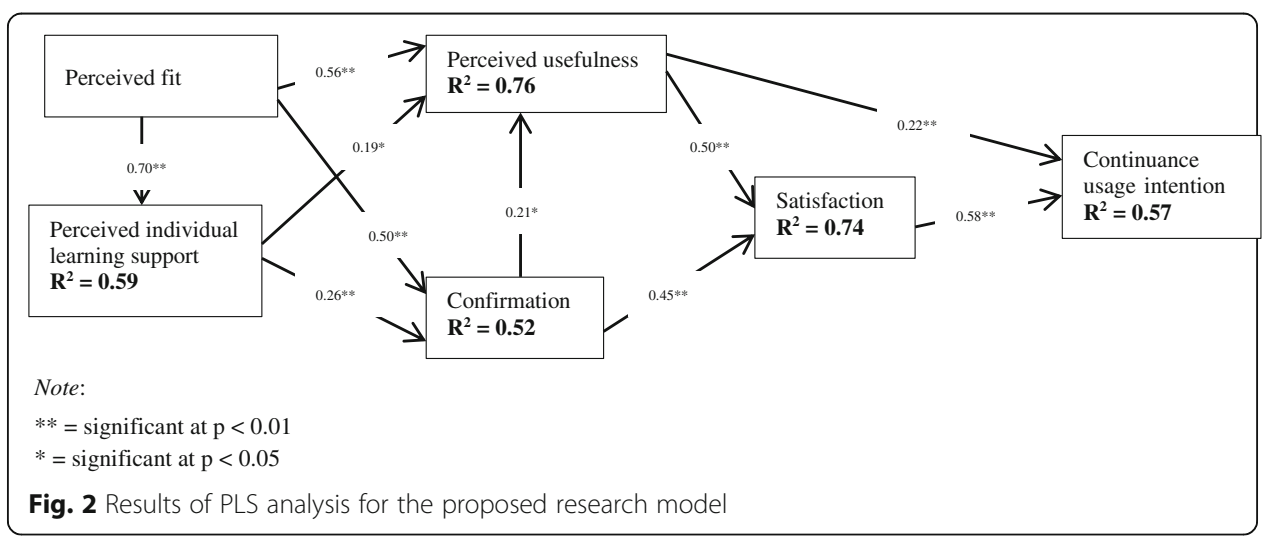


using weblogs to learn the course material when their fit with such technologies is correspondingly high. This result supports previous studies which demonstrated that a significant positive relationship exists between perceived fit and confirmation of the expected consequences of technology use in learning environments (e.g., McGill \& Klobas, 2009; Lin, \& Wang, CH., 2012; Terzis et al., 2013). With regard to students using weblogs to learn MIS, their perceived individual learning support was found to have a significant effect on perceptions of the usefulness of the technology (H3). This result is analogous to those reported by others investigating similar phenomena (e.g., Sørebø et al., 2009; Cho et al., 2009; Liu et al., 2010; Cheng et al., 2011; Lowe et al., 2013).

$\mathrm{H} 4$, which predicted that the factor of perceived individual learning support would have a positive effect on confirmation of expectations of using weblogs to learn MIS, was supported by the data. Previous research has suggested that individual learning support (e.g., perceptions of user-interface design, system support, functionality, and learning motivation) can be the key antecedents of confirmation of expected benefits of using such tools (e.g., Chiu et al., 2005; Tao et al., 2009; Liu et al., 2010; Cheng et al., 2011).

With respect to students using weblogs to learn MIS, perceived fit was found to have a positive effect on their perceived individual learning support (H5). This finding is consistent with espoused views by other researchers who investigated comparable relationships (e.g., Akkoyunlu \& Soylu, 2008; McGill \& Hobbs, 2008; Lin, \& Wang, CH., 2012; Terzis et al., 2013). Confirmation of the expected benefits of using weblogs to learn MIS is an important predictor of perceived usefulness of such tools by students (H6). Studies by Tang et al. (2014) and Chen et al. (2015), who examined the effect of confirmation on perceived usefulness in the context of weblog learning, offered a view comparable to the one being presented herein.

The data confirms $\mathrm{H} 7$ to show that perceived usefulness has a positive effect on satisfaction with weblogs usage. That is, students using weblogs to learn in a MIS course were more satisfied when their perceptions of the usefulness of such tools were equally high. In other words, perceived usefulness of weblogs is a strong predictor of satisfaction with usage of such tools for learning courses such as MIS. Several prior studies of ICT-enabled learning environments and weblog usage by students have provided strong evidence to support the foregoing claim (Limayem \& Cheung, 2008; Sørebø et al., 2009; Lee, 2010; Liao et al., 2015; Tang et al., 2014; Chen et al., 2015). H8 was confirmed to show that students using weblogs to learn MIS were satisfied when their expectations of the benefits of using such tools were confirmed. This result is in agreement with the findings reported in other studies (Sørebø et al., 2009; Stone \& Baker-Eveleth, 2013; Liao et al., 2015; Tang et al., 2014; Chen et al., 2015).

The result for $\mathrm{H} 9$ clearly indicates that students who are satisfied with the use of weblogs for learning in the MIS class are more likely to continue using the technology for such purposes in the future. As per H10, the data shows that when students' perceptions of the usefulness of weblogs are high, their continued intent to use such technologies will correspondingly be high. These findings are consistent with the observations in previous comparable studies confirming the positive effects of perceived usefulness and satisfaction on students' continued intention to use ICT-enabled learning technologies (Limayem \& Cheung, 2008; Stone \& Baker-Eveleth, 2013; Liao et al., 2015; Tang et al., 2014; Chen et al., 2015). 


\section{Theoretical implications}

This study has contributed to research on continuance usage intention of weblogs in higher educational contexts. Perspectives of students' intention to continue using blogging to learn MIS enriches and diversifies knowledge in the area. This study demonstrates that ECM is a valuable framework for explaining students' continued intention to use weblogs for learning purposes. This study offers further support for the suitability of ECM in predicting continued usage intention of ICT products. In this study, ECM was infused with two relevant antecedents, i.e., perceived fit and perceived individual learning support, which were shown to be pertinent antecedents to continued intention to use weblogs, at least, in the context of students' use of such tools to learn in a MIS course.

This study lends credence to previous work that showed that factors such as perceived fit, perceived individual learning support, perceived usefulness, confirmation, and satisfaction have positive effects on students' continuance usage intention in ICTsupported learning environments. This current endeavor opens up an opportunity for theory development in the area of continuance usage intention of technologies in higher educational contexts. Other researchers can expand this study's research model by incorporating other intrinsic motivational and affective factors (e.g., perceived selfefficacy, perceived playfulness, affect, and anxiety) to deepen understanding.

It is worth pointing out that this study found students' satisfaction with weblog use to be the strongest predictor of continuance usage intention followed by perceived usefulness. Other weblog studies revealed a similar result (e.g., Chen et al., 2015; Tang et al., 2014); however, studies of other ICT-enabled learning technologies found perceived usefulness to be strongest predictor of students' intention to continue using this technology (e.g., Limayem \& Cheung, 2008). Furthermore, some other studies revealed that student satisfaction was unrelated to their intention to continue using e-learning technology. Information similar to that noted herein can be beneficial for future inquires in the area.

\section{Practical implications}

Regarding encouraging students' continuance intention to use weblogs for learning MIS, the results of this study provide useful directions for instructors and other practitioners. One key practical implication from this research is that students' satisfaction with weblogs use for learning MIS is the most important proximal antecedent of future usage intentions. Thus, MIS instructors should find ways to ensure that students are generally pleased with using weblogs to learn the course content. For instance, incentives similar to those offered to student participants taking the MIS course used in this study could be considered. Namely, blogging tasks as part of course work could be made quasi-mandatory and instructors should endeavor to grade or mark such assignments (Luik \& Taimalu, 2016).

In an attempt to ensure students continue using weblogs to learn MIS or related courses, instructors could promote the tangible usefulness or benefits of weblog usage for learning. Practical information on how such tools help students enhance learning effectiveness should be communicated (Lowe et al., 2013). For instance, several comments received from students in the study showed that through the MIS blogging task, they were able to gain deeper understanding of the various MIS concepts through both 
the self-reflection on their own postings and interaction with peer postings. Admittedly, the instructor's knowledge of certain topics was enhanced by students' postings on emerging concepts and advances in MIS not currently captured or reflected in the course textbook. Furthermore, the instructor observed an improvement in students' performance in the course. Namely, the class average score in the preceding four MIS classes was 69.7\%; the mean score for the four classes in which weblogs were used was $72.3 \%$. Even though, the increase may appear marginal, it still shows an upward trend in student performance in the course. It is important to stress that the conditions (e.g., similar class size, same textbook, same instructor, similar student attributes) were constant in both cohorts. Sharing information about the potential benefits of blogging for learning will enhance their perceptions of the usefulness of such tools for learning, which in turn leads to continued use of such technologies.

Confirmation of expected benefits of using weblogs to learn MIS or related courses lead to higher satisfaction levels with such technologies. To that end, an instructor may provide initial training opportunities or orientation classes on what to expect with regard to using weblogs for learning purposes; such exposure ultimately facilitates intentions to continue using these technologies. Given that weblog use leverages a learner's autonomy in the learning space, instructors using such technologies while teaching ever-evolving subjects such as MIS must not adopt a rigid mindset on what they deem 'known facts'. As indicated, students using weblogs in this study uncovered and posted new information not yet included their course text.

Perceived fit and perceived individual learning support are important antecedents to the core constructs of ECM. To that end, it is recommended that instructors of MIS and similar courses could provide basic training to students on how to align beliefs, learning needs, and approaches with weblogs used in learning spaces. Lai et al. (2012) noted that it is only when students feel that the use of a particular technology is compatible with their learning styles, expectations, and beliefs, will they be inclined to initially adopt the technology for learning and continue using such. Administrators in the higher education sector who wish to introduce weblogs in their institutions could create supportive environments by encouraging efforts which seek to align such tools with students' and teachers' styles and needs. Blog service providers should continue to develop tools that can leverage the learning styles and needs of users such as students. Such an alignment, if achievable, can foster positive attitudes toward weblogs, which is promising for sustained use of such tools by students.

\section{Limitations and future research directions}

There are limitations in this study. The study's sample size is small; however, as noted, PLS places minimal requirements on sample sizes. This study used a convenience sample, which was constrained by extraneous factors in the research location. As a consequence, selection bias might exist for the study. A random sampling method removes selection bias. Similarly, non-response bias cannot be ruled out as the views of students who did not use weblogs to learn in the MIS classes were not sampled. As the research participants were undergraduate students, the findings reported in the study cannot be applied to all contexts, including post graduate students and working professionals. Data was collected from one location; thus, the generalizability of the results to all 
locations and settings is not advised. A cross-sectional survey was used to collect data. Empirical data from a longitudinal survey offers a more robust capability for predicting behavior over time. The sampled students' views of blogging were presented from the viewpoint of a single course: MIS. It is not certain if the same results would be uncovered for other academic courses.

Future research on the topic can expand this current effort by considering the following areas. First, the noted limitations in the research project should be addressed. Second, follow-up studies could compare students' continued usage intention of weblogs use for learning MIS and related courses. Third, improving the generalizability of the results, other settings (e.g., larger universities and other countries) could be considered. Fourth, the research model used for the study did not include all possible factors that could serve as potential antecedents to continued usage intention. Future research should incorporate the effects of factors such as computer habits, perceived competence, perceived enjoyment, techno-phobia, and so on to increase knowledge in the area.

\section{Conclusion}

Based on ECM, which was fused with the intrinsic motivational factors related to perceived fit and perceived individual learning support, this study investigated undergraduate students' continuance usage intention of weblogs in a MIS course. The results confirmed that perceived fit, perceived individual learning support, perceived usefulness, confirmation, and satisfaction are key predictors of students' intention to continue using weblogs for learning in a MIS class. Notably, perceived fit and perceived individual learning support are important antecedents to continued usage of weblogs for the sampled students. Research on students' adoption and continued use of blogging tools for learning in higher education contexts, is enriched by this effort.

Acknowledgements

The study was conducted solely by the author of the paper.

Ethics approval and consent to participate

The Research Ethics Board of Cape Breton University, Canada approved the study.

Competing interests

The study was supported by an internal funding grant received from Cape Breton University, Canada.

\section{Publisher's Note}

Springer Nature remains neutral with regard to jurisdictional claims in published maps and institutional affiliations.

Received: 27 July 2017 Accepted: 10 January 2018

Published online: 23 January 2018

\section{References}

Akkoyunlu, B., \& Soylu, M. Y. (2008). A study of student's perceptions in a blended learning environment based on different learning styles. Educational Technology \& Society, 11(1), 183-193.

Al Waely, S., \& Aburezeq, I. M. (2013). Using blogs to facilitate interactive and effective learning: Perceptions of preservice arabic teachers. Journal of Language Teaching and Research, 4(5), 975-985.

Ames, P. C. (2003). Gender and learning style interactions in students' computer attitudes. Journal of Educational Computing Research, 28(3), 231-244.

Arquero, J. L., \& Romero-Frías, E. (2013). Using social network sites in higher education: An experience in business studies. Innovations in Education and Teaching International, 50, 238-249.

Au, A. K., \& Enderwick, P. (2000). A cognitive model on attitude toward technology adoption. Journal of Managerial Psychology, 15(4), 266-282.

Benedict, L., \& Pence, H. E. (2012). Teaching chemistry using student-created videos and photo blogs accessed with smartphones and two-dimensional barcodes. Journal of Chemical Education, 89(4), 492-496.

Bennett, S., Bishop, A., Dalgarno, B., Waycott, J., \& Kennedy, G. (2012). Implementing web 2.0 technologies in higher education: A collective case study. Computers \& Education, 59, 524-534. 
Bhattacherjee, A. (2001). Understanding information systems continuance. An expectation-confirmation model. MIS Quarterly, 25(3), 351-370.

Black, L. (2007). Blogging clicks with educators: Online forums make assignments, ideas more accessible to students and parents. Knight Ridder Tribune Business New.

Brown, L. V. (2007). Psychology of motivation. New York: Nova Science Publishers.

Buzzard, C., Crittenden, V. L., Crittenden, W. F., \& McCarty, P. (2011). The use of digital technologies in the classroom: A teaching and learning perspective. Journal of Marketing Education, 33(2), 131-139.

Cakir, H. (2013). Use of blogs in pre-service teacher education to improve student engagement. Computers \& Education, 68, $244-252$.

Castaneda, D., Ahern, T., \& Díaz, S. (2011). Teaching and learning the Spanish aspect using blogs and wikis: An exploratory study. IALLT Journal of Language Learning Technologies, 41(1), 64-89.

Chen, C.-P., Lai, H.-M., \& Ho, C. Y. (2015). Why do teachers continue to use teaching blogs? The roles of perceived voluntariness and habit. Computers \& Education, 82, 236-249.

Chen, J.-L. (2011). The effects of education compatibility and technological expectancy on e-learning acceptance. Computers \& Education, 57, 1501-1511.

Cheng, B., Wang, M., Yang, S. J. H., Kinshuk, \& Peng, J. (2011). Acceptance of competency-based workplace e-learning systems: Effects of individual and peer learning support. Computers \& Education, 57, 1317-1333.

Cheng, Y.-M. (2014). What drives nurses' blended e-learning continuance intention? Educational Technology \& Society, 17(4), $203-215$.

Chickering, A. W., \& Gamson, Z. F. (1987). Seven principles for good practice in undergraduate education. American Association for Higher Education Bulletin, 39(7), 3-7.

Chiu, C. M., Hsu, M. H., Sun, S. Y., Lin, T. C., \& Sun, P. C. (2005). Usability, quality, value and e-learning continuance decisions. Computers and. Education, 45(4), 399-416.

Cho, V., Cheng, T. C. E., \& Lai, W. M. J. (2009). The role of perceived user-interface design in continued usage intention of self-paced e-learning tools. Computers \& Education, 53, 216-227.

Costa, C., Alvelos H., \& Teixeira, L. (2015). The use of Web 2.0 tools by students in learning and leisure contexts: a study in a Portuguese institution of higher education. Technology, Pedagogy and Education, 25(3), 377-394.

Coutinho, C. P. (2007). Cooperative learning in higher education using weblogs: a study with undergraduate students of education in Portugal. World Multi-Conference on Systemics, Cybernetic and Informatics, 11, Orlando, USA, pp. 60-64.

Davis, F. D. (1989). Perceived usefulness, perceived ease of use, and user acceptance of information technology. MIS Quarterly, 13(3), 319-340

Deng, L., \& Yuen, A. (2011). Towards a framework for educational affordance of blogs. Computers \& Education, 56(2), $441-451$.

Deng, L., \& Yuen, A. H. K. (2013). Blogs in pre-service teacher education: Exploring the participation issue. Technology. Pedagogy and Education, 22(3), 339-356.

Draganidis, F., \& Mentzas, G. (2006). Competency-based management: A review of systems and approaches. Information Management \&Computer Security, 14, 51-64.

Edwards, J. R. (2008). Person-environment fit in organizations: An assessment of theoretical progress. The Academy of Management Annals, 2, 167-230

Ellison, N. B., \& Wu, Y. (2008). Blogging in the classroom: A preliminary exploration of student attitudes and impact on comprehension. Journal of Educational Multimedia and Hypermedia, 17(1), 99-122.

Fornell, C., \& Larcker, D. F. (1981). Evaluating structural equations models with unobservable variables and measurement error. Journal of Marketing Research, 8(1), 39-50.

Gefen, D., \& Straub, D. (2005). A practical guide to factorial validity using PLS-graph: Tutorial and annotated example. Communications of the Association for Information Systems, 16, 91-109.

Goodhue, D., \& Thompson, R. L. (1995). Task-technology fit and individual performance. MIS Quarterly, 19(2), $213-236$.

Gurzick, D. \& Lutters, W.G. (2006). From the personal to the profound: Understanding the blog life cycle. In: Proceedings of the CHI 2006, April 22-27. Montreal, Canada: ACM Press, 827-832.

Hain, S., \& Back, A. (2008). Personal learning journal - Course design for using weblogs in higher education. Electronic Journal of e-Learning, 6, 189-195.

Hair, J., Black, W. C., Babin, B. J., \& Anderson, R. E. (2010). Multivariate data analysis (7th ed.). Upper saddle River, New Jersey: Pearson Education International.

Hair, J. F., Ringle, C. M., \& Sarstedt, M. (2011). PLS-SEM: Indeed a silver bullet. Journal of Marketing Theory and Practice, 19(2), 39-152

Halic, O., Lee, B., Paulus, T., \& Spence, M. (2010). To blog or not to blog: Student perceptions of blog effectiveness for learning in a college-level course. The Internet and Higher Education, 13(4), 206-213.

Herrington, J., \& Oliver, R. (2000). An instructional design framework for authentic learning environments. Educational Technology Research and Development, 48(3), 23-48.

Horton, S. (2000). Introduction- the competency-based movement: Its origins and impact on the public sector. The International Journal of Public Sector Management, 13, 306-318.

Hung, M.-C., Chang, I.-C., \& Hwang, H.-G. (2011). Exploring academic teachers' continuance toward the web-based learning system: The role of causal attributions. Computers \& Education, 57, 1530-1543.

Ifinedo, P. (2007). Investigating the antecedents of continuance intention of course management systems use among Estonian undergraduates. International Journal of Information and Communication Technology Education, 3(4), 76-92.

Ifinedo, P. (2016). Assessing students' satisfaction with blog usage for learning: Focus on perceived enjoyment, knowledge sharing experience, and technology acceptance factors. In the Proceedings of the 27th IBIMA Conference, 4-5 May 2016, Milan. IBIMA Publishing LLC, King of Prussia.

Ifinedo, P. \& Usoro, A. (2016). Students' intention to continue using blogs for learning: An analysis of influencing factors, the 2016 International Conference on Information Technology and Economic Development (ICITED), July, 6-9, 2016, Calabar, Nigeria. University of Calabar Press, Calabar.

Kaplan, M. D., Piskin, B., \& Bol, B. (2010). Educational blogging: Integrating technology into marketing experience. Journal of Marketing Education, 32(1), 50-63.

Kim, H. N. (2008). The phenomenon of blogs and theoretical model of blog use in educational contexts. Computers \& Education, 51(3), 1342-1352. 
Kock, N. (2015). WarpPLS 5.0 User Manual, ScriptWarp Systems, http://cits.tamiu.edu/WarpPLS/UserManual_v_5_0.pdf. Kristof-Brown, A. L., Zimmerman, R. D., \& Johnson, E. C. (2005). Consequences of individuals' fit at work: A meta-analysis of person-job, person-organization, person-group, and person-supervisor fit. Personnel Psychology, 58, 281-342.

Lai, C., Wang, Q., \& Lei, J. (2012). What factors predict undergraduate students' use of technology for learning? A case from Hong Kong. Computers \& Education, 59, 569-579.

Lai, H., \& Chen, C. (2011). Factors influencing secondary school teachers' adoption of teaching blogs. Computers \& Education, 56, 948-960.

Lee, M.-C. (2010). Explaining and predicting users' continuance intention toward e-learning: An extension of the expectation-confirmation model. Computers \& Education, 54, 506-516.

Lenhart A, Purcell K, Smith A, \& Zickuhr K. (2010). Social media and mobile Internet use among teens and young adults, Available at http://www.pewinternet.org/files/old-media/Files/Reports/2010/PIP_Social_Media_and_Young_Adults_ Report_Final_with_toplines.pdf. Accessed 2 June 2016.

Liao, Y.-W., Huang, Y.-M., \& Wang, Y.-S. (2015). Factors affecting students' continued usage intention toward business simulation games: An empirical study. Journal of Educational Computing Research, 53(2), 260-283.

Limayem, M., \& Cheung, C. M. K. (2008). Understanding information systems continuance. The case of internet-based learning technologies. Information Management, 45(4), 227-232.

Lin, W.-S. (2012). Perceived fit and satisfaction on web learning performance: IS continuance intention and tasktechnology fit perspectives. International Journal Human-Computer Studies, 70(7), 498-507.

Lin, W.-S., \& Wang, C. H. (2012). Antecedences to continued intentions of adopting e-learning system in blended learning instruction: A contingency framework based on models of information system success and tasktechnology fit. Computers \& Education, 58, 88-99.

Liu, I.-F., Chen, M. C., Sun, Y. S., Wible, D., \& Kuo, C.-H. (2010). Extending the TAM model to explore the factors that affect intention to use an online learning community. Computers \& Education, 54, 600-610.

Lowe, B., D'alessandro, S., Winzar, H., Laffey, D., \& Collier, W. (2013). The use of web 2.0 technologies in marketing classes: Key drivers of student acceptance. Journal of Consumer Behaviour, 12, 412-422.

Lu, H., \& Lee, M. (2012). Experience differences and continuance intention of blog sharing. Behaviour \& Information Technology, 31(11), 1081-1095.

Luik, P., \& Taimalu, M. (2016). Factors of participants and blogs that predict blogging activeness during teaching practice and induction year. International Review of Research in Open and Distributed Learning, 17(1), 190-194.

Mansouria, S. A., \& Piki, A. (2016). An exploration into the impact of blogs on students' learning: Case studies in postgraduate business education. Innovations in Education and Teaching International, 53(3), 260-273.

McGill, T. J., \& Hobbs, V. J. (2008). How students and instructors using a virtual learning environment perceive the fit between technology and task. Journal of Computer Assisted Learning, 24(3), 191-202.

McGill, T. J., \& Klobas, J. E. (2009). A task-technology fit view of learning management system impact. Computers \& Education, 52, 496-508.

Merrill, M. D. (1975). Learner control: Beyond aptitude-treatment interactions. Educational Technology Research and Development, 23(2), 217-226.

Oliver, R. L. (1980). A cognitive model for the antecedents and consequences of satisfaction decisions. Journal of Marketing Research, 17, 460-469.

Paulus, T., Payne, R., \& Jahns, L. (2009). Am I making sense here?: What blogging reveals about undergraduate student understanding. Journal of Interactive Online Learning, 8(1), 1-22.

Robertson, J. (2011). The educational affordances of blogs for self-directed learning. Computers \& Education, 57, 628-1644.

Shim, J. P., \& Guo, C. (2009). Weblog technology for instruction, learning, and information delivery. Decision Sciences Journal of Innovative Education, 7(1), 171-193.

Sørebø, Ø., Halvari, H., Gulli, V. F., \& Kristiansen, R. (2009). The role of self-determination theory in explaining teachers' motivation to continue to use e-learning technology. Computers \& Education, 53(4), 1177-1187.

Stone, R. W., \& Baker-Eveleth, L. (2013). Students' expectation, confirmation, and continuance intention to use electronic textbooks. Computers in Human Behavior, 29, 984-990.

Sun, Y.-C. (2010). Developing reflective cyber communities in the blogosphere: A case study in Taiwan higher education. Teaching in Higher Education, 15, 369-381.

Tang, J. E., Tang, T., \& Chiang, C. (2014). Blog learning: Effects of users' usefulness and efficiency towards continuance intention. Behaviour \& Information Technology, 33(1), 36-50.

Tao, Y.-H., Cheng, C. J., \& Sun, S.-Y. (2009). What influences college students to continue using business simulation games? The Taiwan experience. Computers \& Education, 53, 929-939.

Terzis, V., Moridis, C. N., \& Economides, A. A. (2013). Continuance acceptance of computer based assessment through the integration of user's expectations and perceptions. Computers \& Education, 62, 50-61.

Vygotsky, L. S. (1978). Mind in society: The development of higher psychological processes. Cambridge, MA: Harvard University Press.

Wagner, N., Hassanein, K., \& Head, M. (2008). Who is responsible for e-learning success in higher education? A stakeholders' analysis. Educational Technology \& Society, 11(3), 6-36.

Williams, J. B., \& Jacobs, J. (2004). Exploring the use of blogs as learning spaces in the higher education sector. Australasian Journal of Educational Technology, 20(2), 232-247.

Wu, J., Tsai, R. J., Chen, C. C., \& Wu, Y. (2006). An integrative model to predict the continuance use of electronic learning systems: Hints for teaching. International Journal on E-Learning, 5(2), 287-302.

Yang, S.-H. (2009). Using blogs to enhance critical reflection and community of practice. Educational Technology \& Society, 12(2), 11-21.

Zhang, H., Song, W., Shen, S., \& Huang, R. (2014). The effects of blog-mediated peer feedback on learners' motivation, collaboration, and course satisfaction in a second language writing course. Australasian Journal of Educational Technology, 30(6), 670-685. 